\title{
Superoxide dismutase reduces the impairment of endothelium-dependent relaxation in the spontaneously hypertensive rat aorta
}

\author{
Fumiko SeKIGUCHI ${ }^{1}$, Aiko YANAMOTO ${ }^{1}$ and Satoru SUNANO ${ }^{1}$ \\ ${ }^{1}$ School of Pharmaceutical Sciences, Kinki University, Higashi-Osaka, Osaka 577-8502, \\ Japan
}

\begin{abstract}
The involvement of the superoxide anion in endothelium-dependent relaxation (EDR) was examined in noradrenaline-contracted aortic smooth muscle preparations isolated from normotensive Wistar Kyoto rats (WKY) and stroke-prone spontaneously hypertensive rats (SHRSP). Acetylcholine (ACh, $10^{-9}-10^{-5} \mathrm{M}$ ) induced EDR in both WKY and SHRSP preparations in a concentration-dependent manner, but with a significantly smaller amplitude in those from SHRSP than in those from WKY. The ACh-induced EDR was inhibited by $\mathrm{N}^{\omega}$-nitro-L-arginine (L-NOARG), in a concentration-dependent manner, both in WKY and SHRSP. The EDR produced in WKY in the presence of $3 \times 10^{-6} \mathrm{M} \mathrm{L}$ NOARG was similar in magnitude to that produced in SHRSP in the absence of LNOARG. Superoxide dismutase (SOD, 300 units $/ \mathrm{ml}$ ) increased the amplitude of EDR in SHRSP but not in WKY, with no alteration of the threshold or of the maximal amplitude. The maximal amplitude of EDR produced in SHRSP in the presence of SOD was still smaller than that in WKY. In WKY, a possible involvement of superoxide in the EDR was examined in aortae whose EDR was partially inhibited by treatment with a subthreshold concentration $\left(3 \times 10^{-6} \mathrm{M}\right)$ of L-NOARG. In the L-NOARG-conditioned aorta, the reduced EDR was partially but significantly recovered by SOD. These results suggest that the impaired EDR in aortae of SHRSP may be causally related to a higher production of superoxide. The L-NOARG-induced inhibition of EDR in WKY may be produced, in part, by the reduction of effective NO due to its destruction by superoxide.
\end{abstract}

Key words: superoxide, stroke-prone spontaneously hypertensive rats (SHRSP), aorta, endothelium-dependent relaxation, nitric oxide

\section{Introduction}

Endothelium-dependent relaxation (EDR) has been reported to be impaired in arteries of spontaneously hypertensive rats (SHR) and stroke-prone SHR (SHRSP), to an extent dependent on age and degree of hypertension (Hongo et al., 1988; Sunano et al., 1989; Tominaga et al.,

Correspondence to: Dr. Fumiko Sekiguchi, Division of Physiology and Pathophysiology, School of Pharmaceutical Sciences, Kinki University, 3-4-1 Kowakae, Higashi-Osaka, Osaka 577-8502, Japan

Phone: +81-6-6721-2332 (ext. 3815) Fax: +81-6-6730-1394 e-mail: fumiko@phar.kindai.ac.jp 
1994; Lang et al., 1995; Mantelli et al., 1995; Sunano et al., 2000). The cause of the impairment varies between different arteries. For example, it has been shown to be due to the decreased release or response to endothelium-derived relaxing factor (EDRF) (Grunfeld et al., 1995; Hirata et al., 1996), to increased release of endothelium-derived contracting factor (EDCF) (Lüscher and Vanhoutte, 1986; Watt and Thuston, 1989; Diederich et al., 1990) and to decreased endothelium-dependent hyperpolarization (Fujii et al., 1992, 1993; Sunano et al., 1999).

EDRF may be nitric oxide (NO) (Palmer et al., 1987), and the production of NO from Larginine could be blocked by $\mathrm{N}^{\omega}$-nitro-L-arginine (L-NOARG) (Moore et al., 1990). Since EDRs of the aortae of both normotensive Wistar Kyoto rats (WKY) and SHRSP are largely inhibited by L-NOARG, it is considered that the EDRs are produced mainly by NO (Sekiguchi et al., 1996). The reduction of EDR in SHRSP aortae may be the result of a decreased release of NO or a decreased response of smooth muscle to NO. However, the evidence from several studies indicates that a decreased release of NO is the more likely cause of the reduction, since the response of vascular smooth muscle to NO is not decreased in the aortae of SHRSP (Koga et al., 1989; Osugi et al., 1990; Tesfamariam and Ogletree, 1995). NO is destroyed by the superoxide anion (Gryglewski et al., 1986; Palmer et al., 1987), and superoxide is broken down by superoxide dismutase (SOD) (Gryglewski et al., 1986). Thus it is possible that the reduced EDR of aorta in these hypertensive animals could be reversed by SOD. This is supported by the evidence that EDRs in the aortae of SHR and SHRSP are improved by SOD, possibly because it prevents the destruction of NO by superoxide (Nakazono et al., 1991; Grunfeld et al., 1995).

The present experiments were carried out to investigate a possible involvement of superoxide in the impairment of EDR in the aortae of SHRSP, and the results were compared with those obtained in aortae of WKY treated with L-NOARG.

\section{Materials and Methods}

\section{Animals}

Rats used in the present experiment were handled according to the "Guiding Principles for the Care and Use of Animals in the Field of Physiological Sciences" of the Physiological Society of Japan.

Male SHRSP and normotensive WKY were used in the present experiments. These rats were obtained from Shimizu Laboratory Supplies Co. Ltd. (Kyoto, Japan) at the age of 4 weeks and maintained in our animal facility until they were sacrificed. The rats were killed at the age of 16 weeks by bleeding from the anterior venae cavae during $\mathrm{CO}_{2}$ anesthesia. Aortae were removed from the thoracic cavity and immersed in a modified Tyrode's solution described below.

\section{Solutions}

The composition of the modified Tyrode's solution was (mM): $\mathrm{NaCl}, 137 ; \mathrm{KCl}, 5.4 ; \mathrm{CaCl}_{2}$, 2.0; $\mathrm{MgCl}_{2}, 1.0 ; \mathrm{NaHCO}_{3}, 11.9 ; \mathrm{NaH}_{2} \mathrm{PO}_{4}, 0.4$; glucose, 5.6; equilibrated with a gas mixture of $95 \%$ $\mathrm{O}_{2}$ and $5 \% \mathrm{CO}_{2}$. The $\mathrm{pH}$ of the solution at $37^{\circ} \mathrm{C}$ was 7.3 . High- $\mathrm{K}^{+}$Tyrode's solution containing 50 $\mathrm{mM} \mathrm{K}^{+}$was made by substituting $\mathrm{NaCl}$ in the modified Tyrode's solution for equimolar $\mathrm{KCl}$. 


\section{Preparations}

Ring preparations of the aortae $(1.0 \mathrm{~mm}$ in width) were made by cutting the aorta transversely with fine surgical scissors. In one tenth of the preparations, the endothelium was removed by rubbing the inner surface of the ring preparations gently with a soft rubber band. Two tungsten wires of $30 \mu \mathrm{m}$ diameter were inserted into the lumen of each preparation and then one of them was tied to a plastic holder. This holder was mounted in an organ bath (10 ml) filled with modified Tyrode's solution kept at $37^{\circ} \mathrm{C}$. The other wire was connected to a force transducer (Minebea, Nagano, Japan), so that changes in tension (contraction and relaxation) could be observed isometrically.

\section{Mechanical recording}

Preparations were equilibrated in modified Tyrode's solution for $60 \mathrm{~min}$, then initially subjected to two successive high- $\mathrm{K}^{+}$-induced contractions of $30 \mathrm{~min}$ duration with an interval of $30 \mathrm{~min}$, by changing the incubation medium from normal Tyrode's to high-K Tyrode's solution. After this procedure, the preparations were contracted by $5 \times 10^{-7} \mathrm{M}$ noradrenaline (NA). Ten min after the preparation achieved contraction maximum, acetylcholine (ACh) was applied cumulatively to induce EDR. Superoxide dismutase (SOD) was applied $30 \mathrm{~min}$ before the initiation of the NA contraction and was present throughout both the NA-induced contraction and the ACh-induced relaxation. In the experiment where the relaxation was depressed by LNOARG, SOD $\left(3 \times 10^{-6} \mathrm{M}\right.$ or $\left.10^{-4} \mathrm{M}\right)$ was added to the modified Tyrode's solution 30 min before the initiation of the NA-induced contraction and remained during throughout the contraction and the ACh-induced relaxation.

\section{Drugs}

Drugs used in the present experiment were noradrenaline bitartrate (Sigma, St. Louis, MO, USA), acetylcholine chloride (Wako Chem., Osaka, Japan), $\mathrm{N}^{\omega}$-nitro-L-arginine (Sigma, St. Louis, MO, USA) and bovine erythrocyte superoxide dismutase (SOD, Wako Chem., Osaka, Japan). Stock solutions of noradrenaline, acetylcholine, $\mathrm{N}^{\omega}$-nitro-L-arginine and SOD were prepared by dissolving these chemicals into distilled water at concentrations of $0.1-10 \mathrm{mM}$ or $30,000 \mathrm{unit} / \mathrm{ml}$ for SOD, and they were then added to Tyrode's solution to obtain the desired concentrations. The amount of solvent added in Tyrode's solution did not exceed 1/100 of the solution. The addition of these chemicals to Tyrode's solution did not alter the $\mathrm{pH}$ of the solution.

\section{Statistics}

Results are expressed as the mean \pm S.E.M. with the number of observations in parenthesis. Relaxation responses are expressed as percentages of the NA-induced contraction. Differences between the preparations from WKY and SHRSP, between the values in the presence and absence of L-NOARG, and between the values in the absence and presence of SOD were analyzed using the unpaired Student's-t test, where a $\mathrm{P}$ value smaller than 0.05 was considered to be significant. 
A

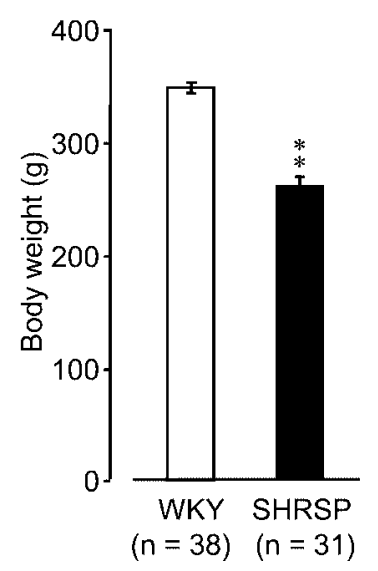

B

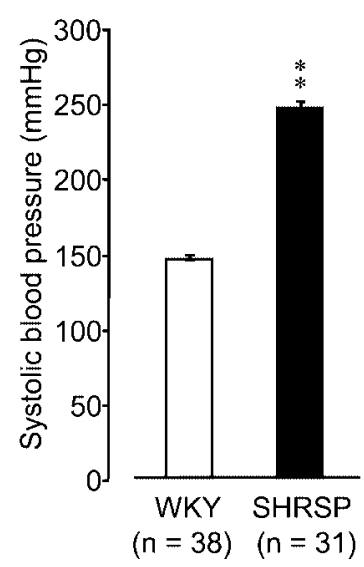

Fig. 1. Body weight (A) and systolic blood pressure (B) of Wistar Kyoto rats (WKY) and stroke-prone spontaneously hypertensive rats (SHRSP) at the age of 16 weeks. Asterisks indicate significant differences from the values of WKY $(* *: P<0.001)$.

\section{Results}

Body weight and blood pressure of rats

The body weight and systolic blood pressure of WKY and SHRSP were measured just before sacrificing the animals. As shown in Fig. 1, while the systolic blood pressure was markedly higher in SHRSP compared to WKY, the opposite was the case for body weight.

\section{Endothelium-dependent relaxation of aortae from WKY and SHRSP}

In aortic rings precontracted with noradrenaline (NA, $\left.5 \times 10^{-7} \mathrm{M}\right)$, acetylcholine (ACh) produced a relaxation response which was absent in tissues after removal of the endothelial cells by rubbing (i.e., endothelium-dependent relaxation, EDR). The amplitude of ACh-induced EDR increased in a concentration-dependent manner, both in SHRSP and WKY (Fig. 2). For both WKY and SHRSP, the threshold concentration of ACh for the EDR was $10^{-10} \mathrm{M}$, with the maximum response at $10^{-6} \mathrm{M}$. The amplitude of the maximum relaxation was significantly $(P<0.001)$ smaller in aortae from SHRSP (about $70 \%$ of NA contraction) than in those from WKY (about $90 \%$ of NA contraction).

Experiments were carried out to test the effects of L-NOARG on the ACh-induced EDR in aortae from WKY and SHRSP. As shown in Fig. 3, the EDR was inhibited by N ${ }^{\omega}$-nitro-L-arginine (L-NOARG, $3 \times 10^{-6}-10^{-4} \mathrm{M}$ ) in a concentration-dependent manner, at any given concentrations of ACh, and EDR was abolished at $10^{-4} \mathrm{M} \mathrm{L-NOARG,} \mathrm{both} \mathrm{in} \mathrm{WKY} \mathrm{and} \mathrm{SHRSP.} \mathrm{In} \mathrm{the} \mathrm{presence}$ of $3 \times 10^{-6} \mathrm{M} \mathrm{L-NOARG}$, the EDR for aortae from WKY was identical to that for aortae from SHRSP in the absence of L-NOARG. These results confirmed the previous observation that in both WKY and SHRSP the ACh-induced EDR was produced mainly by endothelial NO (Sekiguchi et al., 1996). 


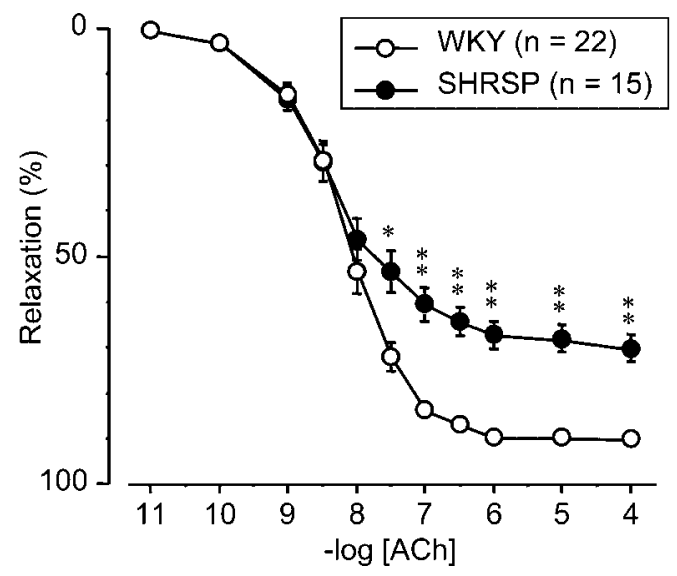

Fig. 2. Concentration-response curves for acetylcholine (ACh)-induced endotheliumdependent relaxation in aortae from WKY (open circles) and SHRSP (filled circles). Aortic rings precontracted by noradrenaline $\left(5 \times 10^{-7} \mathrm{M}\right)$ were stimulated with cumulatively increasing concentrations of ACh $\left(10^{-11}-10^{-4} \mathrm{M}\right)$, and the amplitude of relaxation was expressed as percentage of the contraction produced before application of ACh. Statistical significance in comparison to values in WKY was tested $(*: P<0.05$, **: $P<0.001)$.

A

WKY

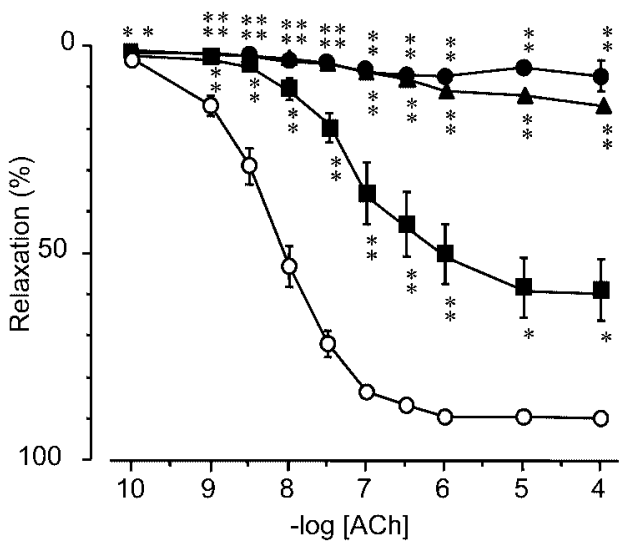

$$
\begin{aligned}
& - \text { Control }(n=22) \\
& \rightarrow \text { L-NOARG } 10^{-4} \mathrm{M}(\mathrm{n}=13) \\
& \leftarrow \text { L-NOARG } 10^{-5} \mathrm{M}(\mathrm{n}=7) \\
& \rightarrow-\text { L-NOARG } 3 \times 10^{-6} \mathrm{M}(\mathrm{n}=12)
\end{aligned}
$$

B SHRSP

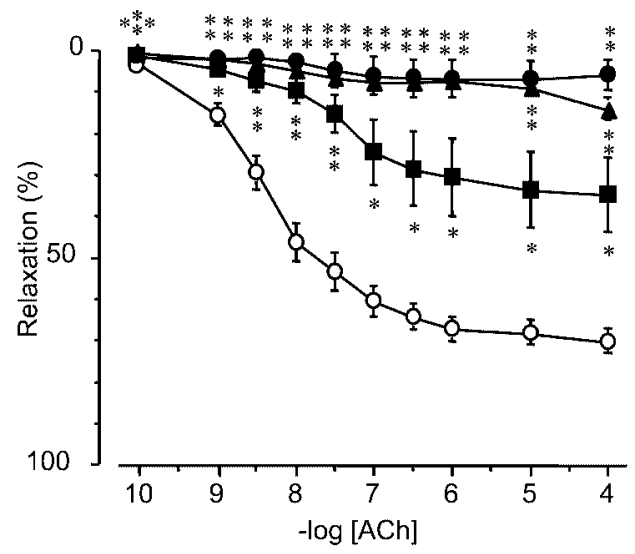

$$
\begin{aligned}
& -0 \text { Control }(\mathrm{n}=15) \\
& \rightarrow-\text { L-NOARG } 10^{-4} \mathrm{M}(\mathrm{n}=7) \\
& \rightarrow \text { L-NOARG } 10^{-5} \mathrm{M}(\mathrm{n}=7) \\
& \rightarrow-\text { L-NOARG } 3 \times 10^{-6} \mathrm{M}(\mathrm{n}=11)
\end{aligned}
$$

Fig. 3. Effects of $\mathrm{N}^{\omega}$-nitro-L-arginine (L-NOARG) on endothelium-dependent relaxation produced by acetylcholine (ACh) in aortae obtained from WKY (A) and SHRSP (B). Aortic rings were contracted by noradrenaline $\left(5 \times 10^{-7} \mathrm{M}\right)$, and cumulative concentrations of ACh $\left(10^{-10}-10^{-4}\right.$ M) were applied in the absence (Control, open circles) and presence of different concentrations of L-NOARG $\left(3 \times 10^{-6} \mathrm{M}\right.$, filled squares; $10^{-5} \mathrm{M}$, filled triangles; $10^{-4} \mathrm{M}$, filled circles). L-NOARG was applied $30 \mathrm{~min}$ before the initiation of noradrenaline-induced precontraction. Statistical significance compared to the values in the absence of L-NOARG (Control) was tested (*: $P<0.05, * *: P<0.001)$. 
A

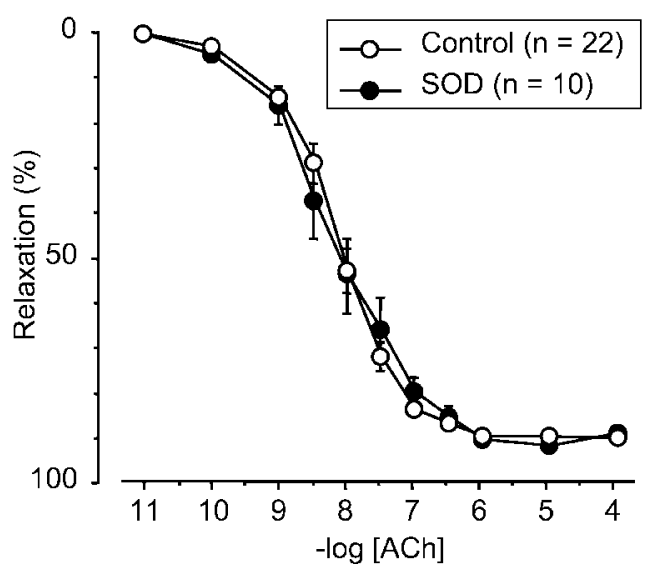

B

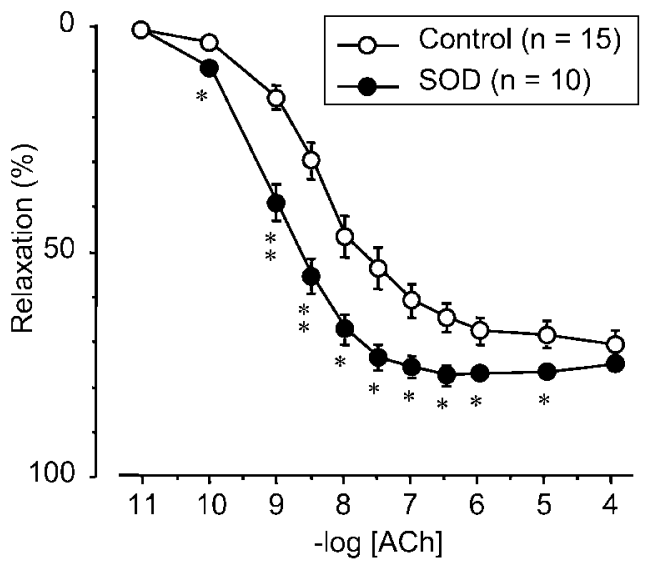

Fig. 4. Effect of superoxide dismutase (SOD) on endothelium-dependent relaxation induced by acetylcholine (ACh) in aortae from WKY (A) and SHRSP (B). Aortic rings were contracted with noradrenalline $\left(5 \times 10^{-7} \mathrm{M}\right)$, and relaxations produced by cumulative application of $\mathrm{ACh}\left(10^{-11}-10^{-4}\right.$ M) were observed before (Control, open circles) and during the presence of SOD (300 units $/ \mathrm{ml}$ ) for over 30 min (filled circles). Statistical significance compared to Control value at each concentration of ACh was tested (*: $\left.P<0.05,{ }^{* *}: P<0.001\right)$.

\section{Effects of superoxide dismutase on endothelium-dependent relaxation}

The effects of superoxide dismutase (SOD) on EDR were studied in aortic rings obtained from WKY and SHRSP. SOD (300 units/ml) did not alter the NA-induced contractions. However in the presence of SOD, the ACh-induced EDR was significantly increased in SHRSP (Fig. 4B) but no significant change was observed in WKY, at any given concentrations of ACh (Fig. 4A). The threshold concentration of ACh required for generation of EDR (equal to $10^{-10}$ M) was also not changed by SOD in both WKY and SHRSP.

Experiments were carried out to observe the effects of SOD on EDR in aortae of WKY which had been partially inhibited by L-NOARG. As shown in Fig. 3, the ACh-induced EDR of WKY produced in the presence of $3 \times 10^{-6} \mathrm{M}$ L-NOARG was identical to the EDR produced in SHRSP in the absence of L-NOARG. In the presence of $3 \times 10^{-6} \mathrm{M}$ L-NOARG, the amplitude of EDR produced in aortae from WKY was again increased by 300 units/mil SOD (Fig. 5). Although the amplitude of EDR produced by each concentration of ACh was smaller in LNOARG-treated aortae from WKY than in those from SHRSP, the maximum amplitude of EDR produced by $10^{-5} \mathrm{M}$ ACh was $58.0 \pm 7.2 \%$ ( $\left.\mathrm{n}=12\right)$ in the absence of SOD and $75.7 \pm 4.1 \%$ ( $\left.\mathrm{n}=10\right)$ in the presence of SOD.

\section{Discussion}

Factors or mechanisms involved in EDR vary between different types of blood vessels (Shepherd and Katusic, 1991; Hwa et al., 1994; Zygmunt, et al., 1995; Shimokawa et al., 1996; Berman and Griffith, 1998; Tare et al., 2000). The present results, that the ACh-induced EDR of 


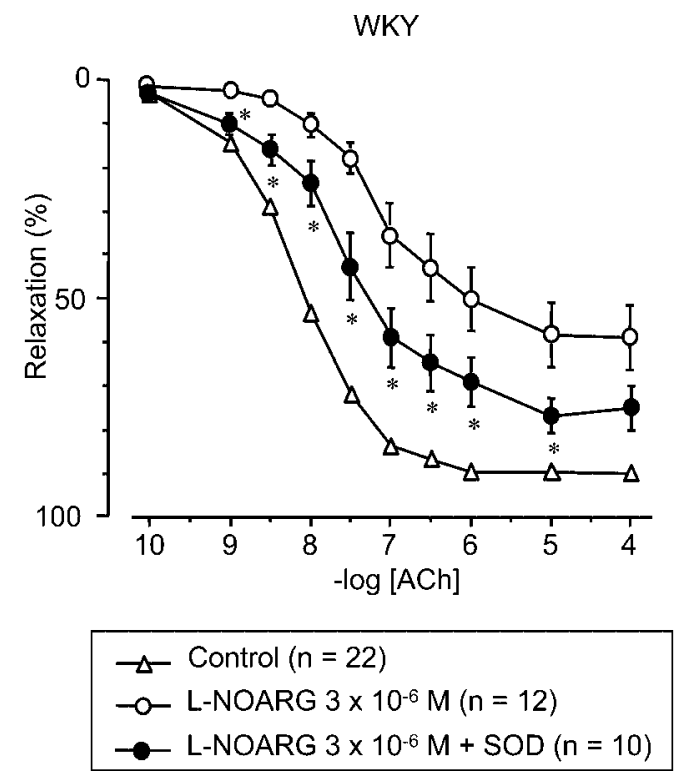

Fig. 5. Effects of SOD on the endothelium-dependent relaxation produced by $\mathrm{ACh}$ in aorta from WKY, in the presence L-NOARG $\left(3 \times 10^{-6} \mathrm{M}\right)$. Aortic rings isolated from WKY were precontracted with noradrenaline $\left(5 \times 10^{-7} \mathrm{M}\right)$, and ACh $\left(10^{-10}-10^{-4} \mathrm{M}\right)$ was applied cumulatively, in the absence (open triangles) and presence of $3 \times 10^{-6} \mathrm{M} \mathrm{L}$ NOARG (open circles) and additional presence of both L-NOARG and $300 \mathrm{units} / \mathrm{ml}$ SOD (filled circles). Amplitude of relaxation relative to that of noradrenaline contraction is shown (mean \pm S.D.). Statistical significance of values obtained in the presence of both L-NOARG and SOD to those in the presence of L-NOARG alone was tested $(*: P<0.05)$.

both WKY and SHRSP aortae was blocked completely by removal of the endothelium or by application of $10^{-4} \mathrm{M}$ L-NOARG, indicate that the EDR is induced by endothelial NO (Sekiguchi et al., 1996). It has been reported that NO is inactivated by superoxide, and thus superoxide may impaire EDR of vascular smooth muscle (Gryglewski et al., 1986; Rubanyi and Vanhoutte, 1986; Laight et al., 1998). In the present experiments, the EDR of NA-contracted aortae was shown to be impaired in preparations from SHRSP, confirming a number of previously reported observations (Lüscher, 1988, and also a review by Sunano et al., 2000). Several mechanisms have been considered to be involved in the impairment of EDR in SHRSP, such as 1) reduced production of $\mathrm{NO}, 2$ ) increased release of endothelium-derived relaxing factors such as endothelium-derived contractile factor (EDCF) and endothelium-derived hyperpolarizing factor (EDHF) or 3) diminished endothelium-dependent hyperpolarization of the smooth muscle membrane. Among these, the reduced release of NO may be the major mechanism for the reduction of EDR in aortae of SHRSP, since the EDR was mainly produced by the L-NOARG sensitive component. This agrees with previous reports that the release of NO is reduced in the aortic endothelium of SHRSP (Malinski et al., 1993; Hirata et al., 1996).

A reduced NO-component of EDR in SHRSP may be produced either by a decreased release of NO from the endothelium or by the increased destruction of NO, since no significant 
difference in the relaxation of aortic smooth muscle to NO donors is observed between WKY and SHRSP (Sunano et al., 2000). Increased destruction of NO may be produced by an interaction between NO and superoxide (Gryglewski et al., 1986; Palmer et al., 1987; Laight et $a l ., 1998)$. In fact, Grunfeld et al. (1995) observed that the release of NO decreased in the endothelial cells from SHRSP and the treatment of rats with SOD increased the release of NO. Pathogenesis of superoxide anion in the initiation of hypertension has also been reported in conventional SHR (Nakazono et al., 1991). Thus, it is reasonable to consider that the increased release of superoxide anion may be one of the responsible mechanisms for the reduced release of NO in SHRSP. Scavenging superoxide by SOD may improve the impaired EDR by the destruction of NO in hypertensive rats. The present experiments confirmed that these were indeed the case in the aorta of SHRSP.

The present experiments showed that in WKY the reduced EDR with L-NOARG was partially recovered by treatment with SOD. The improved EDR by treatment with SOD has been reported in the rat aorta treated with a SOD inhibitor, diethyldithiocarbamate (Laight et $a l ., 1998)$ and also in the L-NOARG-treated cerebral artery (Rosenblum et al., 1992). These results suggest that the effects of SOD would be much more pronounced when production of NO is impaired. The present results showed that SOD showed no effect on EDR in aortae from $\mathrm{WKY}$, and these agree with the report that the enhancing effect of SOD on the release of NO was less in the endothelial cells of WKY, although the release of NO even in the absence of SOD was higher than that of SHRSP in the presence of SOD (Grunfeld et al., 1995). Thus, the present results confirm the functional alteration of aortic tissues in SHRSP, as was observed in the measurement of NO in endothelial cells of hypertensive animals.

The observation that the reduced EDR by L-NOARG was also restored by SOD could be interpreted by assuming the involvement of superoxide in the actions of L-NOARG. Inhibition by SOD of the actions of L-NOARG to EDR has been reported in cerebral arterioles (Rosenblum et al., 1992). Since the enhancement by SOD of EDR in WKY was not observed in the absence of L-NOARG, it is unlikely that superoxide is basically inactivating NO in this preparation. In the partial inhibition by L-NOARG of the production of NO, scavenging superoxide by SOD may augment EDR. These results indicate a possible augmentation of the production of superoxide by L-NOARG or the drug itself may increase the synthesis of superoxide. It is reported that NO synthase (NOS) activates the generation of superoxide and that the actions are blocked by $\mathrm{N}^{\omega_{-}}$ nitro-substituted L-arginine (Heinzel et al., 1992; Pou et al., 1992). Taking these reports into consideration, such a possibility is unlikely. It is also reported that superoxide directly enhances the generation of NO (Hobbs et al., 1994). An alternative explanation is that superoxide is synthesized in the aorta of WKY or as a result of stimulation by ACh, but that the amount of production is too little to alter the relaxation induced by endothelium-derived NO under control conditions, i.e., in the absence of L-NOARG. In the partial inhibition by L-NOARG of the production of NO, the amount of superoxide may be sufficient to impair the relaxation.

It is suggested that the impairment of EDR in the aorta of SHRSP may be partly due to the reduction of effective NO due to its destruction by superoxide. Partial inhibition by L-NOARG of EDR produced in aortae from WKY may be caused, in part, by a mechanism similar to that found in SHRSP, i.e., the reduction of NO due to its destruction by superoxide. 


\section{References}

Berman, R.S. and Griffith, T.M. (1998). Spatial heterogeneity in the mechanisms contributing to acetylcholine-induced dilatation in the rabbit ear. Br. J. Pharmacol. 124: 1245-1253.

Diederich, D., Yang, Z., Bühler, F.R. and Lüscher, T.F. (1990). Impaired endothelium-dependent relaxations in hypertensive resistance arteries involve cyclooxygenase pathway. Am. J. Physiol. 258: H445-H451.

Fujii, K., Ohmori, S., Tominaga, M., Abe, I., Takata, Y., Ohya, Y., Kobayashi, K. and Fujishima, M. (1993). Age-related changes in endothelium-dependent hyperpolarization in the rat mesenteric artery. Am. J. Physiol. 265: H509-H516.

Fujii, K., Tominaga, M., Ohmori, S., Kobayashi, K., Koga, T., Takata, Y. and Fujishima, M. (1992). Decreased endothelium-dependent hyperpolarization to acetylcholine in smooth muscle of the mesenteric artery of spontaneously hypertensive rats. Circ. Res. 70: 660-669.

Grunfeld, S., Hamilton, C.A., Mesaros, S., McClain, S.W., Dominiczak, A.F., Bohr, D.F. and Mialinski, T. (1995). Role of superoxide in the decreased nitric oxide destruction by the endothelium of genetically hypertensive rats. Hypertension 26 [part 1]: 854-857.

Gryglewski, R.J., Palmer, R.M.J. and Moncada, S. (1986). Superoxide anion is involved in the breakdown of endothelium-derived vascular relaxing factor. Nature 320: 454-456.

Heinzel, B., John, M., Klatt, P., Böhme, E. and Mayer, B. (1992). Ca ${ }^{2+} /$ calmodulin-dependent formetion of hydrogen peroxide by brain nitric oxide sythease. J. Biochem. 281: 627-630.

Hirata, Y., Hayakawa, H., Kakoki, M., Tojo, A., Suzuki, E., Kimura, K., Goto, A., Kikuchi, K., Nagano, T., Hirobe, M. and Omata, M. (1996). Nitric oxide release from kidneys of hypertensive rats treated with imidapril. Hypertension 27 [part 2]: 672-678.

Hobbs, A.J., Fukuto, J.M. and Ignarro, L.J. (1994). Formation of free nitric oxide from L-arginine by nitric oxide synthase: direct enhancement of generation by superoxide dismutase. Proc. Natl. Acad. Sci. USA 91: 10992-10996.

Hongo, K., Nakagomi, T., Kassel, N.F., Sasaki, T., Lehman, M., Vollmer, D.G., Tsukuhara, T., Ogawa, H. and Torner, J. (1988). Effects of aging and hypertension on endothelium-dependent vascular relaxation in rat carotid artery. Stroke 19: 892-897.

Hwa, J.J., Ghibaudi, L., Williams, P. and Chatterjee, M. (1994). Comparison of acetylcholine-dependent relaxation in large and small arteries of rat mesenteric vascular bed. Am. J. Physiol. 266: H952H958.

Koga, T., Takata, Y., Kobayashi, K., Takishita, S., Yamashita, Y. and Fujishima, M. (1989). Age and hypertension promote endothelium-dependent contractions to acetylcholine in the aorta on the rat. Hypertension 14: 542-548.

Laight, D.W., Kaw, A.V., Carrier, M.J. and Änggard, E.E. (1998). Interaction between superoxide anion and nitric oxide in the regulation of vascular endothelial function. Br. J. Pharmacol. 124: 238244.

Lang, M.G., Noll, G. and Lüscher, T.F. (1995). Effect of aging and hypertension on contractility of resistance arteries: modulation by endothelial factors. Am. J. Physiol. 269: H873-H844.

Lüscher, T.F. (1988). Endothelial vasoactive substances and cardiovascular disease. Karger, Basel.

Lüscher, T.F. and Vanhoutte, P.M. (1986). Endothelium-dependent contractions to acetylcholine in the aorta of the spontaneously hypertensive rat. Hypertension 8: 344-348.

Malinski, T., Kapturczak, M., Dayharsh, J. and Bohr, D. (1993). Nitric oxide synthase activity in genetic hypertension. Biochem. Biophys. Res. Commun. 194: 654-658.

Mantelli, L., Amerini, S. and Ledda, F. (1995). Roles of nitric oxide and endothelium-derived hyperpolarizing factor in vasorelaxant effect of acetylcholine as influenced by aging and hypertension. J. Cardiovasc. Pharmacol. 25: 595-602.

Moore, P.K., al-Swayeh, O.A., Chong, N.W.S., Evans, R.A. and Gibson, A. (1990). L-N ${ }^{G}$-nitro arginine (LNOARG), a novel, L-arginine-reversible inhibitor of endothelium-dependent vasodilatation in 
vitro. Br. J. Pharmacol. 99: 408-412.

Nakazono, K., Watanabe, N., Matsuno, K., Sasaki, J., Sato, T. and Inoue, M. (1991). Does superoxide underlie the pathogenesis of hypertension. Proc. Natl. Acad. Sci. USA 88: 10045-10048.

Osugi, S., Shimamura, K. and Sunano, S. (1990). Decreased modulation by endothelium of noradrenaline-induced contraction in aorta from stroke-prone spontaneously hypertensive rats. Arch. Int. Pharmacodyn. Ther. 305: 86-99.

Palmaer, R.M.J., Ferrige, A.G. and Moncada, S. (1987). Nitric oxide release account for the biological activity of endothelium-derived relaxing factor. Nature 337: 524-526.

Pou, S., Pou, W.S., Bredt, D.S., Snyder, S.H. and Rosen, G.M. (1992). Generation of superoxide by purified brain nitric oxide synthase. J. Boil. Chem. 267: 24173-24176.

Rosenblum, W.I., Nishimura, H. and Nelson, G.H. (1992). L-NMMA in brain microcirculation of mice is inhibited by blockade of cyclooxygenase and by superoxide dismutase. Am. J. Physiol. 262: H1343-H1349.

Rubanyi, G.M. and Vahoutte, P.M. (1986). Superoxide anions and hyperoxia inactivate endotheliumderived relaxing factor. Am. J. Physiol. 250: H822-H827.

Sekiguchi, F., Adachi, T., Matsubara, H., Matsuda, K., Kita, K., Shimamura, K. and Sunano, S. (1996). Spontaneous and agonist-induced contractions and endothelium-dependent relaxation in aortae from SHRSP and WKY rats under various levels of passive force. Clin. Exp. Pharmacol. Physiol. 23: $483-489$.

Shepherd, J.T. and Katusic, Z.S. (1991). Endothelium-derived vasoactive factors: I Endotheliumdependent relaxation. Hypertension 18 [suppl. III]: III-76-III-85.

Shimokawa, H., Yasutake, H., Fujii, K., Owada, K.M., Nakaike, R., Fukumoto, Y., Takayanagi, T., Nagao, T., Egashira, K., Fujishima, M. and Takeshita, A. (1996). The importance of the hyperpolarizing mechanism increases as the vessel size decreases in endothelium-dependent relaxation in rat mesenteric circulation. J. Cardiovasc. Pharmacol. 28: 703-711.

Sunano, S., Osugi, S. and Shimamura, K. (1989). Blood pressure and impairment of endotheliumdependent relaxation in spontaneously hypertensive rats. Exprientia 45: 705-708.

Sunano, S., Sekiguchi, F. and Shimamura, K. (2000). Arterial smooth muscle tone and its modification by endothelium in spontaneously hypertensive rats. Biomed. Res. 11: 137-147.

Sunano, S., Watanabe, H., Tanaka, S., Sekiguchi, F. and Shimamura, K. (1999). Endothelium-derived relaxing, contracting and hyperpolarizing factors of mesenteric arteries of hypertensive and normotensive rats. Br. J. Pharmacol. 126: 709-716.

Tare, M., Parkington, H.C. and Coleman, H.A. (2000). EDHF, NO and a prostanoid: hyperpolarizationdependent and -independent relaxation in guinea-pig arteries. Br. J. Pharmacol. 130: 605-608.

Tesfamariam, B. and Ogletree, M.L. (1995). Dissociation of endothelial cell dysfunction and blood pressure in SHR. Am. J. Physiol. 269: H189-H194.

Tominaga, M., Fujii, K., Abe. I., Takata, Y., Kobayashi, K. and Fujishima, M. (1994). Hypertension and aging impair acetylcholine-induced vasadilation in rats. J. Hypertens. 12: 259-268.

Watt, P.A.C. and Thuston, H. (1989). Endothelium-dependent relaxation in resistance vessels from the spontaneously hypertensive rats. J. Hypertens. 7: 661-666.

Zygmunt, P.M., Rayman, T. and Högestätt, E.D. (1995). Regionel differences in endothelium-dependent relaxation in the rat: contribution of nitric oxide and nitric oxide-independent mechanisms. Acta Physiol. Scand. 155: 257-266. 